\title{
LUMBAR AND FEMORAL BONE MINERAL DENSITY IN TYPE 2 TURKISH DIABETIC PATIENTS
}

\author{
Günşah Şahın, Selda Bağis, Özlem Bölgen Cımen, Sacettın Özişik, Hayal Güler, Canan Erdoğan \\ Mersin University, School of Medicine, Mersin-Turkey: Department of Physical Medicine and Rehabilitation
}

\begin{abstract}
Summary: The relationship between type 2 diabetes and osteoporosis has not been well established. We studied a population composed of 161 post-menopausal women with type 2 diabetes and a control group. We examined bone mineral density with the dual -energy X-ray absorptiometry(DXA) technique at the lumbar and femoral regions and in a subgroup of patients, we also measured the levels of markers of bone remodelling. We found significantly higher levels of bone mineral density at the lumbar and femoral levels in the diabetic subjects compared with the control group. Moreover, we found higher level of urinary calcium in the controls. On the basis of these results, we suggest that osteoporosis cannot be considered a complication of type 2 diabetes.
\end{abstract}

Key words: Type 2 diabetes; Densitometry; Osteoporosis

\section{Introduction}

Several diseases have been described as a cause of osteoporosis, such as diabetes mellitus but its results are uncertain in type 2 diabetes. Osteopenia is more severe when diabetes begins in the pubertal age and the reduction in the bone mineral density is more significant in the first 5 years after the onset of disease. It is reported that demineralization is also related with the level of $\operatorname{HbA}_{1 \mathrm{C}}(1,2)$. Some authors have reported low bone mineral density (BMD) in patients with type 2 diabetes but other studies found normal or higher levels than normal (1).

Giacca et al. found no differences in radial BMD between control subjects and patients with type 2 diabetes (4). Buysschaert et al. reported low BMD values in male patients with type 2 diabetes but normal values in female patients with type 2 diabetes (2). Kraukauer et al found lower BMD values in type 2 diabetic patients than non diabetic patients (6).

The aim of this study is to examine the osteoporosis in type 2 diabetes and to ascertain whether it is a condition predisposing to reduced BMD.

\section{Subjects and Methods}

We studied 161 post-menopausal diabetic women with mean body mass index (BMI) of $30.17 \pm 4.9 \mathrm{SD}$, the inclusion criterias for the survey were: Diabetes diagnosed at $\geq 30$ years of age and patients who had type 2 diabetes for at least 2 years. We excluded subjects affected by diseases that can influence bone metabolism, history of any systemic diseases, hip and vertebral fracture and subjects treated with insulin and any drug that can interfere with bone turnover.

As a control group, we selected 90 healthy, non-diabetic women of similar age, menopausal age and BMI to diabetic patients. They had no history of any systemic disease, hip and vertebral fracture and drug administration that can interfere with bone metabolism.

In diabetic patients, no subjects had high creatine levels. The two groups were similar for physical activity and no history of smoking and previous history of hormone therapy. Patients with clinically relevant scoliosis or ectopic calcification were excluded.

We examined BMD at the lumbar and femoral regions. The levels of the following markers of the bone remodeling were measured: Calcium, phosphorus, total alkaline phosphatase (ALP) and osteocalcin, in the serum. We also evaluated calcium (mg) in the 24 -h- urine sample collected in the morning after an overnight fast.

Bone mineral density was assessed using the DXA technique (hologic QDR 4500). Our results are expressed as BMD $\left(\mathrm{g} / \mathrm{cm}^{2}\right)$ and $\mathrm{T}$ score. The serum levels of calcium and phosphorus were measured by an enzymatic system and osteocalcin by RIA. Urinary calcium, was determined by calorimetric assay with endpoint determination in Roche diagnostics. ALP was dosed by IFCC.

The data were analyzed by student $t$ test and $p$ value $\leq 0.01$ were considered as statistically significant.

\section{Results}

Body mass index, age, menarj age and menopause duration were not significantly different between the diabetic 
patients and controls (Tab. 1). We did not find significant differences between diabetic and control subjects in the levels of serum calcium, phosphorus, ALP, and osteocalcin (Tab. 2).

Significant difference was found between two groups in the level of urinary calcium which was higher in the controls than diabetics $(\mathrm{p}=0.005)$.

Bone mineral density, measured at the lumbar $\left(\mathrm{L}_{2}-\mathrm{L}_{4}\right)$ and femoral (neck and total hip) regions were higher in type 2 diabetic patients than controls (Tab. 3).

In diabetic patients, there was no correlation between age and BMD of the lumbar, femoral neck and total hip. The duration of diabetes did not correlated with BMD. However, BMI correlated with BMD of the femoral neck and total hip $(\mathrm{r}=0.236, \mathrm{r}=0.330, \mathrm{p}<0.01)$ but not with lumbar spine $\left(\mathrm{L}_{2}-\mathrm{L}_{4}\right)$.

Tab. 1: Characteristics of examined subjects (mean $\pm \mathrm{SD}$ ).

\begin{tabular}{|l|c|c|c|c|}
\hline & $\begin{array}{c}\text { Age } \\
\text { (years) }\end{array}$ & $\begin{array}{c}\text { Menopause } \\
\text { (years) }\end{array}$ & $\begin{array}{c}\text { BMI } \\
\left(\mathrm{kg} / \mathrm{m}^{2}\right)\end{array}$ & $\begin{array}{c}\text { Menarche } \\
\text { age (years) }\end{array}$ \\
\hline $\begin{array}{l}\text { Diabetic } \\
\text { subjects } \\
(\mathrm{n}=161)\end{array}$ & $61.06 \pm 7.4$ & $14.6 \pm 8$ & $30.17 \pm 4.9$ & $13.11 \pm 0.8$ \\
\hline $\begin{array}{l}\text { Control } \\
\text { subjects } \\
(\mathrm{n}=90)\end{array}$ & $60.3 \pm 7.4$ & $13.4 \pm 8$ & $28.73 \pm 4.4$ & $13.28 \pm 1.1$ \\
\hline P-value & 0.456 & 0.278 & 0.22 & 0.300 \\
\hline
\end{tabular}

Tab. 2: Bone mineral density (BMD), $\mathrm{T}$ score, $\mathrm{Z}$ score at lumbar and femoral level in diabetic patients and in the control group (mean $\pm \mathrm{SD}$ ).

\begin{tabular}{|l|c|c|c|}
\hline & $\begin{array}{c}\text { Diabetic } \\
\text { subjects }\end{array}$ & $\begin{array}{c}\text { Control } \\
\text { subjects }\end{array}$ & P-value \\
\hline $\mathrm{L}_{2}-\mathrm{L}_{4}$ & $0.893 \pm 0.1$ & $0.780 \pm 0.1$ & 0.00 \\
\hline $\mathrm{T}-$ Score & $-2.05 \pm 1.1$ & $-2.9 \pm 0.7$ & 0.01 \\
\hline Z-Score & $-0.402 \pm 1.2$ & $-1.3 \pm 1.4$ & 0.01 \\
\hline Femur (neck) & $0.765 \pm 0.1$ & $0,708 \pm 0.1$ & 0.00 \\
\hline T-Score & $-1.6 \pm 1.0$ & $-2.1 \pm 0.8$ & 0.01 \\
\hline Z-Score & $0.2 \pm 0.9$ & $-0.3 \pm 0.9$ & 0.01 \\
\hline Total hip & $0.802 \pm 0.1$ & $0.856 \pm 0.4$ & 0.00 \\
\hline T-Score & $-1.2 \pm 0.8$ & $-1.6 \pm 0.6$ & 0.01 \\
\hline Z-Score & $-0.1 \pm 0.9$ & $-0.6 \pm 0.8$ & 0.01 \\
\hline
\end{tabular}

Tab. 3: Levels of markers in diabetics and controls \pm mean (SD).

\begin{tabular}{|l|c|c|c|}
\hline & $\begin{array}{c}\text { Diabetic } \\
\text { subjects }\end{array}$ & $\begin{array}{c}\text { Control } \\
\text { subjects }\end{array}$ & P-value \\
\hline Calcium (mg/dl) & $8.2 \pm 0.12$ & $8.5 \pm 0.16$ & 0.46 \\
\hline Phosphorus (mg/dl) & $4.1 \pm 0.14$ & $4.3 \pm 0.16$ & 0.35 \\
\hline ALP (U/1) & $195 \pm 20$ & $190 \pm 15$ & 0.23 \\
\hline Osteocalcin (ng/ml) & $\begin{array}{c}28.82 \pm 1.4 \\
(\mathrm{n}=60)\end{array}$ & $\begin{array}{c}26.72 \pm 3.2 \\
(\mathrm{n}=58)\end{array}$ & 0.32 \\
\hline Urinary-calcium & $122 \pm 58.0$ & $147 \pm 67.9$ & 0.005 \\
\hline
\end{tabular}

\section{Discussion}

DEXA technique is preferable to the methods used for the evaluation of bone mineral density for its high precision and accuracy, low radiation dose and rapidity of execution (1). Our data agree with these of other authors who used the same technique.

We conclude that BMD is higher in patients with non insulin treated type 2 diabetes when compared with healthy subjects at the same age and sex. In addition, we did not observe evidence of greater bone resorption in the patients affected by type 2 diabetes than in normal subjects. Glisemic control may also protect type 2 diabetic patients and decreases bone turnover as in our diabetic patients (3).

At lumbar and femoral levels in the diabetic group, protection of cortical and trabecular bone which is inconsistent with the result of Isaia et al. (5). They explained the difference of BMD at lumbar and femoral levels by protection of cortical bone (5). They also found lower levels of PTH and urinary crosslinks in diabetics then in the control group $(5,12)$.

Van Daele PL et al. found higher than normal BMD in type 2 diabetic subjects, but Tuominen et al. found similar BMD values in type 2 diabetic patients and controls (14). Tuominen et al. also found lower BMD in type 2 diabetic men then women (13). Sex difference may be explained by the obesity (13).

Our study does not confirm the results of previous studies that reported similar BMD values in type 2 diabetic and control subjects. Anabolic effect of hyperinsulinemia in patients with type 2 diabetes may result in increased bone mineral density by favoring osteoblastic activity. Obesity is also associated with increased BMD as a result of hyperinsulinemia (8).

Pepkern et al. reported that patients with non insulin dependent diabetes mellitus and especially overweight women have a normal or increased BMD (9). Rishway et al. suggested that BMI is more important determinant of BMD then hyperinsulinemia (10). However, Sosa et al. found that diabetic patients were obese with a higher body mass index than controls and there was no evidence that non insulin dependent diabetes mellitus causes any change in bone mineral density (11). In the study, we found statistically significant correlation between BMI and BMD of the femoral neck and total hip in diabetic patients.

Kwon et al. suggested that age, duration of diabetes and menopause duration in diabetics appear to be the risk factors for decreased BMD at the lumbar vertebra (7). We did not find any correlation between these factors and BMD in our diabetic patients.

From a clinical point of view, we conclude that, bone mineral density is higher in patients with type 2 diabetes with non insulin treated when compared with normal subjects. Osteoporosis can not be considered as a complication of diabetes, but further studies are needed to explain the mechanism pathophysiologically. 


\section{References}

1. Barrett CE, Kritz SD. Does hyperinsulinemia preserve bone. Diabetes Care 1996;19 (12):1388-92.

2. Buysschaert M, Cauwe F, Jamart J. Proximal femur density in type 1 and type 2 diabetic patients. Diabete Metab 1992;18:32-37.

3. Christensen JO, Svendsen OL. Bone mineral in pre and postmenopausal women with insulin dependent and non insulin dependent diabetes mellitus. Osteoporosis Int 1999;10 (4):307-11.

4. Giacca A, Fassina A, Caviezel F. Bone mineral density in diabetes mellitus. Bone 1988;9:29-36.

5. Isaia GC, Ardissone P, Di Stefeno M. Bone metabolism in type 2 diabetes mellitus. Acta Diabetotogica 1999;36 (1-2):35-8.

6. Krauker JC, McKenna MJ, Buderer NF. Bone loss and bone turnover in diabetes. Diabetes 1995;44:775-821.

7. Kwon DJ, Kim JH, Chung KW. Bone mineral density of the spine using DEXA in patients with non insulin dependent diabetes mellitus. J Obstet Gynaecol Res 1996;22 (2): 157-62.

8. Okazaki R, Totsuka Y, Hamano K. Metabolic improvement of poorly controlled non insulin dependent diabetes mellitus decreases bone turnover. J Clin Endocrinol Metab 1997;82 (9):2915-20.

9. Pepkorn B, Kann P, Forst T. Bone mineral density and bone metabolism in diabetes mellitus. J Diabetes Complications 1996;10:201-5.
10. Rishway V, Birkeland KI, Falch JA. Bone mass in non insulin dependent diabetes mellitus. Scand J Clin Lab Invest 1995;55 (3):257-62.

11. Sosa M, Dominquez M, Navarro MC. Bone mineral metabolism is normal in non insulin dependent diabetes mellitus.J Diabetes Complications 1996;10:201-205.

12. Suzuki K, Sugimoto C, Takizawa M. Correlation between bone mineral density and circulating bone metabolic markers in diabetic patients. Diabetes Res Clin Pract 2000:48 (3):185-91.

13. Tuominen JT, Impivaara O, Puukka P. Bone mineral density in patients with type 1 and type 2 diabetes. Diabetes Care 1999;22 (7):1196-2000.

14. Van Daele PL, Stolle RD, Burger H. Bone density in non insulin dependent diabetes mellitus. Ann Intern Med 1995;122:409-14

Submitted July 2001.

Accepted November 2001.

Dr. Günşah Şahin,

Fatih mah. 13 sokak, Istanbul evleri, C blok 1-1, Mezitli-Mersin 33170,

Turkey. e-mail: gunsahsahin@hotmail.com 